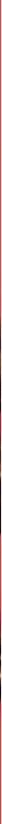

Pedro Ccopacatty. La tragedia de los dioses (detalle). 


\title{
Ccopacatty: perfil de un creador relámpago ${ }^{1}$
}

\author{
Carlos Maza \\ Investigador independiente \\ carlosmazap@gmx.com \\ Lima -Perú
}

\begin{abstract}
Resumen
Peruko Ccopacatty es un escultor egresado de la Escuela Nacional Superior Autónoma de Bellas Artes del Perú (Ensabap) a principios de la década de 1980 emigró a los Estados Unidos, donde ha realizado una incansable labor de producción escultórica y mural especialmente en espacios públicos. Reconocida por instituciones públicas y privadas de su país de residencia, e incluso por la misma Organización de las Naciones Unidas, su obra ha pasado injustamente inadvertida en el Perú. Este artículo describe su proceso a la luz de las escasas fuentes disponibles y a partir de la exposición homenaje, realizada en mayo y junio del 2019 en el Centro Cultural de Bellas Artes como parte de las actividades de conmemoración del Centenario de la Ensabap. Se revisan su estilo, su simbolismo y su trayectoria, y se proponen líneas de investigación hacia el rescate de un corpus disperso y el reconocimiento de su sorprendente trayectoria.
\end{abstract}

Palabras clave: tradición aymara, arte en espacios públicos, Ensabap, escultura en metal, multiculturalidad, muralismo, Pedro Peruko Ccopacatty.

\begin{abstract}
Peruko Ccopacatty is a sculptor graduated from the Ensabap, who emigrated to the United States in the early 80's, where he has carried out a tireless work of sculptural and mural production, especially in public spaces. Recognized by public and private institutions in his country of residence, and even by the United Nations itself, his work has gone unjustly unnoticed in Peru. This article describes his process in light of the scarce sources available and the homage exhibition held in May and June 2019 at the Centro Cultural de Bellas Artes as part of the activities to commemorate the Centennial of Ensabap. Its style, symbolism and trajectory are reviewed, and lines of investigation are proposed towards the rescue of a dispersed corpus and the recognition of its amazing trajectory.
\end{abstract}

Keywords: art in public spaces, aymara tradition, Ensabap, metal sculpture, monumental art, multiculturality, mural painting, Pedro Peruko Ccopacatty.

1 El autor agradece al Centro Cultural de Bellas Artes, a Ccopacatty, a Rosalee Pike y a Millard Llanque, los materiales y fotografías facilitados para la elaboración del presente artículo. 


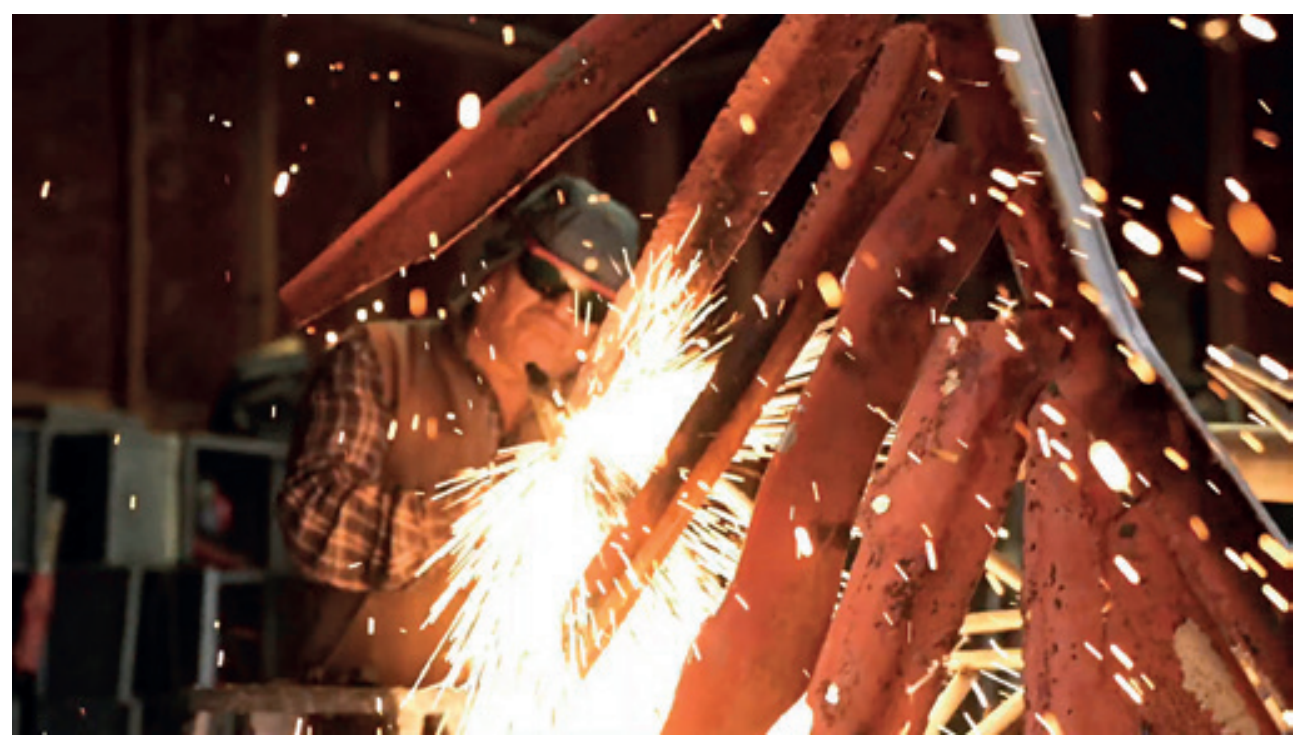

Ccopacatty en su taller. Video All the metals come to him.

Soy un imán.

Los metales vienen a mí.

Peruko Ccopacatty

\section{Introducción}

La semblanza que muestra su página oficial en internet [http://www.ccopacatty.com/aboutthe-artist/] abre con una fotografía del artista, encaramado como un jinete, sobre una de sus piezas -una particularmente oxidada-, enmascarado con goggles de soldador. Martillo en alto, es como un dios-guerrero de los Andes listo para ingresar a un panteón de superhéroes. Y, a su modo, este artista es efectivamente un héroe. La narrativa de su vida transporta los misterios de su ancestralidad aymara y de su temprana necesidad expresiva propia; su trayectoria avanza sobre no pocos obstáculos y desarrolla un estilo poderoso a contragolpe de las tendencias de su tiempo, pero en diálogo con ellas. Como sucede siempre, sin sumarse a manifiesto político alguno, su obra es políticamente más fuerte que la de los cientos de artistas militantes de su tiempo, entre ellos muchos miembros de las promociones bellasartinas que protagonizaron las primeras tomas e intentos de transformación desde abajo de la Escuela. Migrante, aymara, de origen campesino, pero de oficio proletario -el martillo, el metal-, trasciende los prejuicios de la sociedad criolla de Lima (de la que es endémica Bellas Artes), y después trasciende a la sociedad criolla misma, al migrar, de nuevo, a los Estados Unidos. Héroe dos veces, autoexiliado desde la subalternidad, dos veces incrustado con éxito, imponiendo condiciones, en una sociedad que cree ser superior a aquella de la que él procede.

\section{Esbozo biográfico}

Nacido en las orillas del lago Titicaca en 1946, el artista de herencia aymara se trasladó a Lima para estudiar escultura en una Escuela de Bellas Artes que acababa de ver suspendida su autonomía por decisión del Gobierno Revolucionario de las Fuerzas Armadas, dando fin a la "época dorada" de Ugarte Eléspuru y sus secuelas, cuando la Escuela se encontraba en esa plenitud cómoda y ausente de los conflictos de la nación. En Bellas Artes, desde la 


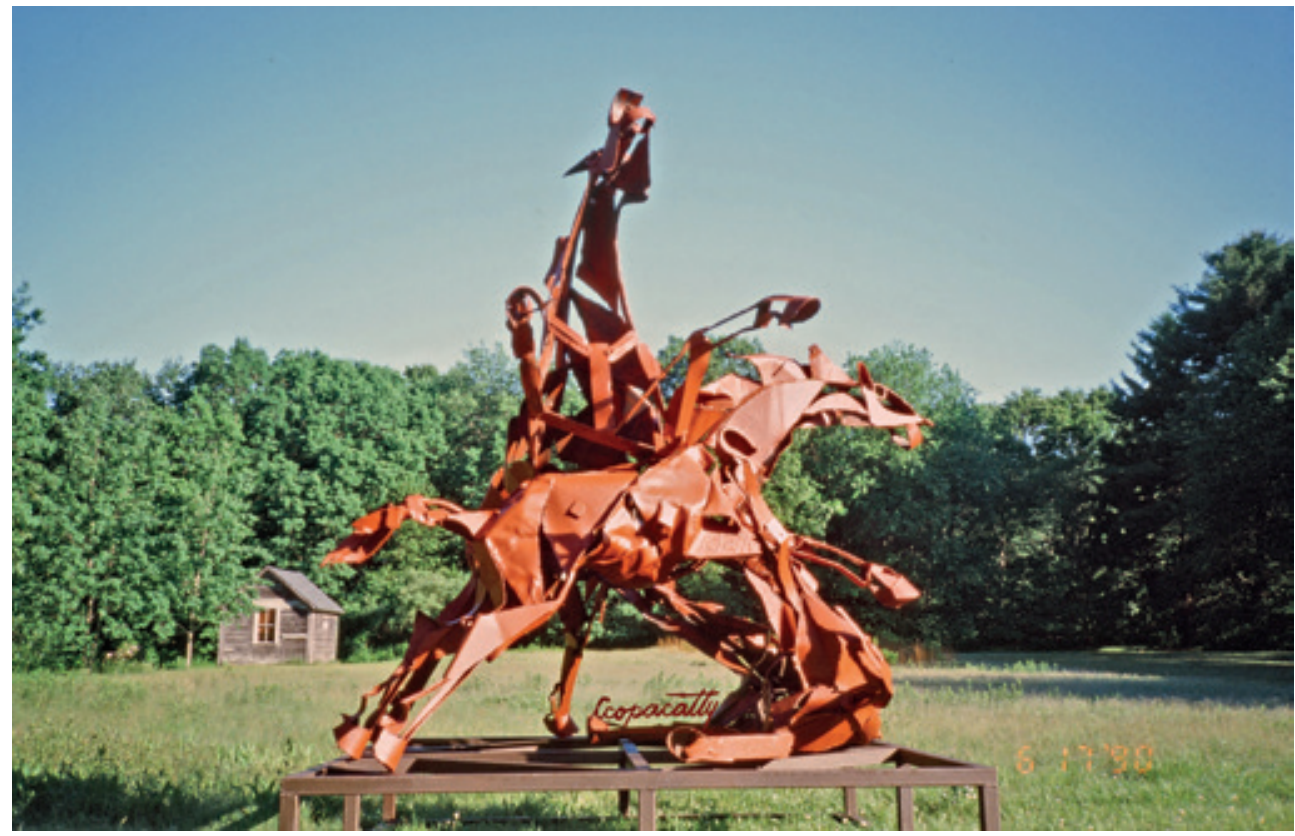

Caballos salvajes. Hierro. Rhode Island.

“promoción de Oro”, la de Tilsa, Cajahuaringa, Quintanilla y Gerardo Chávez, más de diez años atrás, no se había visto ningún proyecto que destacara a esa altura, mientras decaía un mercado del arte discretamente exitoso en la Lima de los 70 y se gestaban los colectivos de vanguardia de una nueva generación. Ccopacatty avanzaría en su propia dirección, llevado por su imperiosa necesidad expresiva, resistente como el acero.

Según una nota aparecida en La República (Loayza, 2005), Pedro Peruko Ccopacatty comenzó a dibujar siendo niño en las riberas del Titicaca. Dibujaba lo que veía en sus trayectos de 10 kilómetros para ir a la escuela desde su casa en aquella comunidad de Socca, situada en una pequeña península, casi un islote, unos 35 kilómetros al sureste de la ciudad de Puno. En la nota de 2005, producto de una entrevista con el artista, Ccopacatty refiere que dibujaba carros y aviones; "nunca pensaba que iba a tener un carro y que volaría en aviones" (Ibídem). Loayza cuenta que Ccopacatty:

Escapó hacia Puno y después a Moquegua para trabajar cuidando animales.

Los campesinos que querían ver sus casitas y vaquitas ilustradas, le pagaban, y Peruko las dibujaba. Eso hasta que un señor le dijo que debía estudiar, porque como pastor de ganado no iba a lograr nada. Terminó la secundaria becado.

Entonces pensó en Lima para estudiar arte y volvió a tirar dedo. Logró ingresar a Bellas Artes. Era el estudiante sin casa. Se fue a dormir con delincuentes debajo de los puentes del río Rímac, hasta que una noche le propusieron realizar un gran robo y se marchó.

Anécdotas disparadas por el artista -como una citada por Chaman (2019, p. 4), en la que dice que se ganaba la vida acarreando bultos en La Parada- contribuyen al halo de misterio que rodea su trayectoria, pero la ausencia de cuidado en el registro de logros y proyectos responde más bien a un impulso que lo lleva a la siguiente obra sin preocuparse demasiado por el destino de la anterior. 
Una vez en Bellas Artes, informa Loayza (Op.Cit.), desarrolla su carrera en situación de precariedad. En un conversatorio recientemente realizado en el Centro Cultural de Bellas Artes, sus colegas Camulfo Vivanco (2019) y Humberto Hoyos (2019) han relatado anécdotas de la época; cuando permanecía por la noche en la Escuela, durmiendo en las poltronas y tarimas de los modelos, comiendo cualquier cosa, y cómo finalmente fue hospedado por la familia de Vivanco con quien establecería una sólida amistad.

En estas condiciones, Ccopacatty realizó una carrera de esfuerzo y se dedicó con pasión al estudio, a la lectura, a conocer la literatura y la música Occidente y sus otras tradiciones estéticas, Loayza (2005) informa que incluso estudió teatro y música, así como que pensaba originalmente en viajar a Europa, no a los Estados Unidos. Optó por las artes plásticas; quizá no lo sabía aún, pero era ya un hombre-imán, los metales lo exigían y a ellos orientó una búsqueda humanista. Podríamos decir que en Bellas Artes, Ccopacatty absorbió la historia cultural de Occidente y la interpretó desde su herencia, su lengua madre, su procedencia; la tradujo al aymara y en el proceso colocó esa tradición en el flujo de la cultura universal.

Aunque volvería después al Perú, donde dejaría huellas, como las figuras de Transformación que parecen volar en la fachada de la biblioteca de la Universidad del Altiplano en Puno; Síntesis de la humanidad, el relieve mural casi flotante del Hospital Nacional Dos de Mayo y La tragedia de los dioses, relieve similar recuperado por el artista y la Dirección de Promoción Cultural de la Ensabap para la muestra Ccopacatty. Una vida de fuego y metal, ha sido en los Estados Unidos, con centro primero en Virginia y luego en Rhode Island, donde Ccopacatty ha desarrollado a plenitud su obra. Estableció un taller y comenzó a realizar obras de gran formato que fueron ganando la atención de la comunidad cultural local y regional. Pronto sus piezas estarían repartidas por la costa noreste de los Estados Unidos.

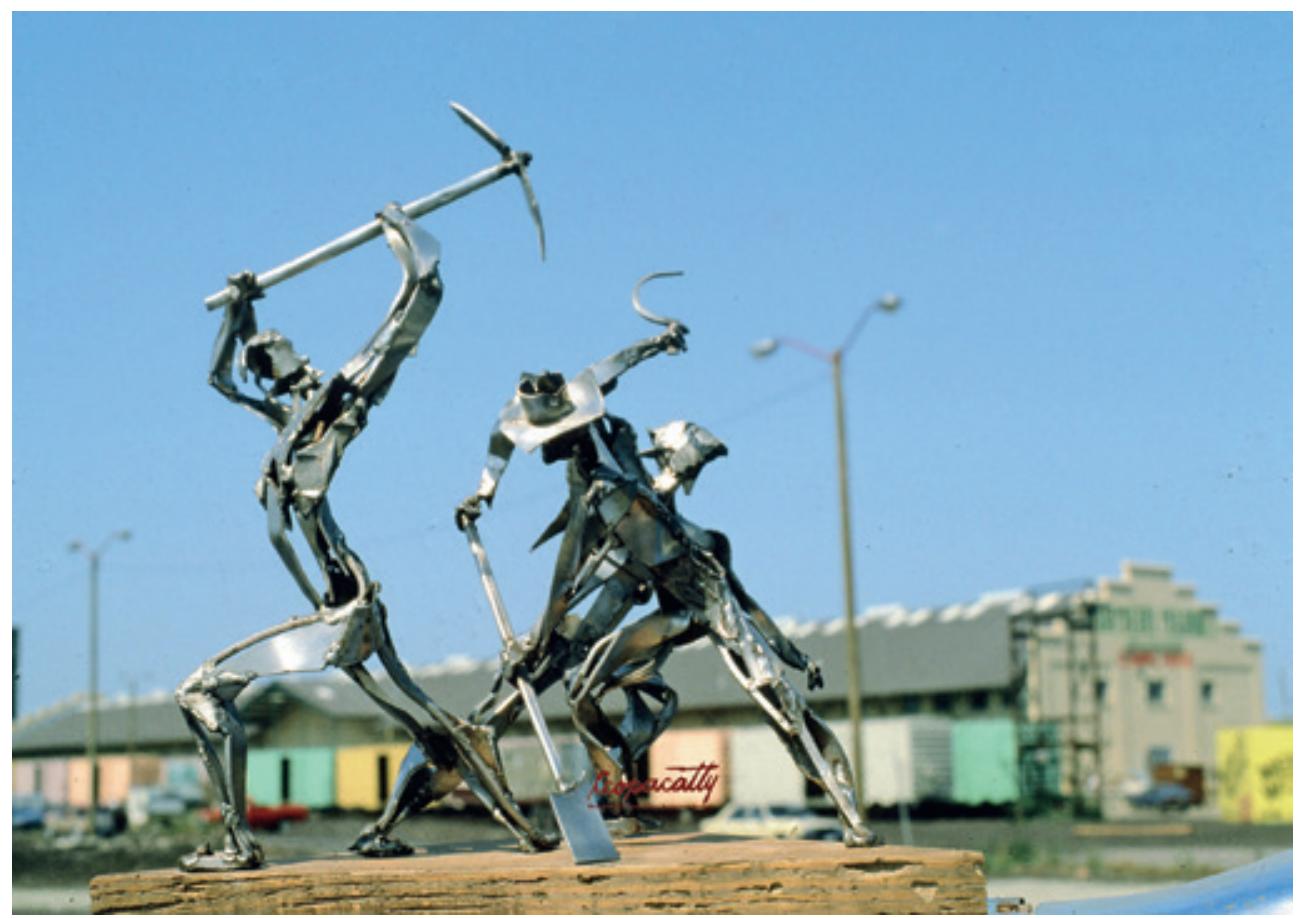

Chacra. Acero inoxidable. Rhode Island. 


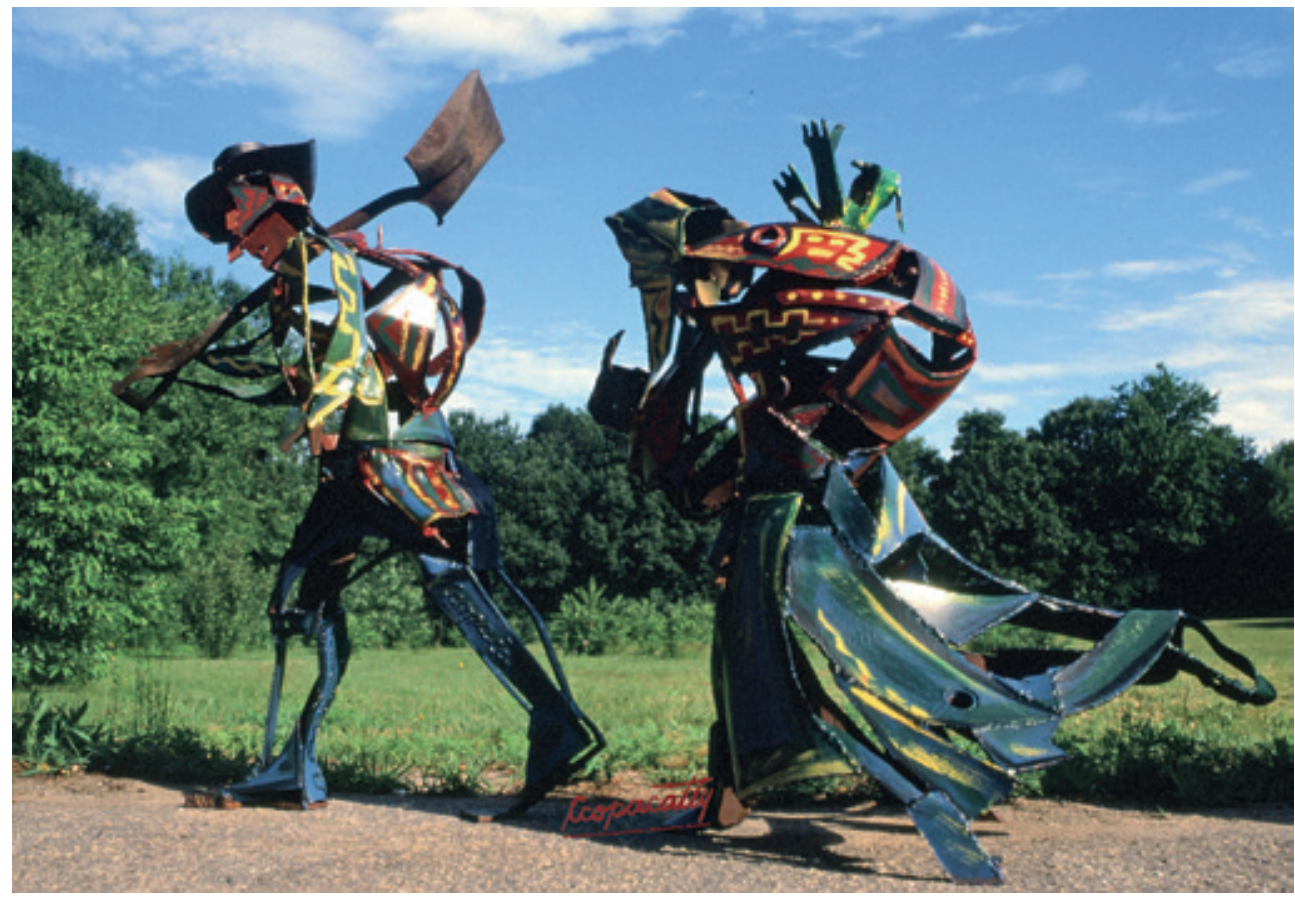

Familia andina. Acero. Rhode Island.

En alianza creativa con Rosalee Pike -una alianza que continúa hasta nuestros días-, poeta y ensayista estadounidense, curadora y gestora con quien contrajo matrimonio, Ccopacatty volvió a filtrar el universo cultural que lo rodeaba a través de esa mirada aymara vuelta universal gracias al exitoso paso por la academia en el Perú. Luego de graduarse siguió entre los muros de Bellas Artes especializándose en escultura de gran formato a través de prácticas con los más importantes fundidores de la época (Hoyos, 2019; Vivanco, 2019). Pero no sería la fundición su destino, un modo quizás demasiado ventajoso para domar al metal. Recordemos que el vaciado en bronce, por más grande que sea, se realiza a través de la "trampa" del modelado en yeso o algún otro material suave que será remplazado, a través del poder industrial de la fundición, por el metal derretido. Ccopacatty prefirió dar forma al hierro y al acero en el taller del herrero: en la forja a martillazos, en el corte a máquina y la soldadura directa. En comparación con la fundición, esta estrategia pone al artista-obrero al tú por tú con la materia, un choque de dos portentos.

En los Estados Unidos donde aterrizó en mayo de 1981, apenas cuatro años después de haber egresado de Bellas Artes, con medalla de oro en escultura en 1976 (Ccopacatty, s. f.), encontró un universo efervescente en las artes. Habían pasado ya las vanguardias de los 60 , dejando senderos abiertos para la experimentación y también un más sólido y amplio mercado para el arte nuevo. Terminada la guerra de Vietnam y a punto de dar el giro hacia la derecha de la era Reagan-Bush, los movimientos sociales pacifistas y de oposición al establishment se desarticularon y tendieron a desaparecer en el inevitable proceso de comercialización, de conversión del arte en mercancía, tan característico del sistema del arte en aquel país: la revolución se volvía un show de TV (Bell, 1977). Pero el espíritu comunalista del hippismo y su tendencia a incorporar elementos simbólicos de culturas subalternas -la búsqueda de raíces africanas de los movimientos de negritud disparados por las luchas por 


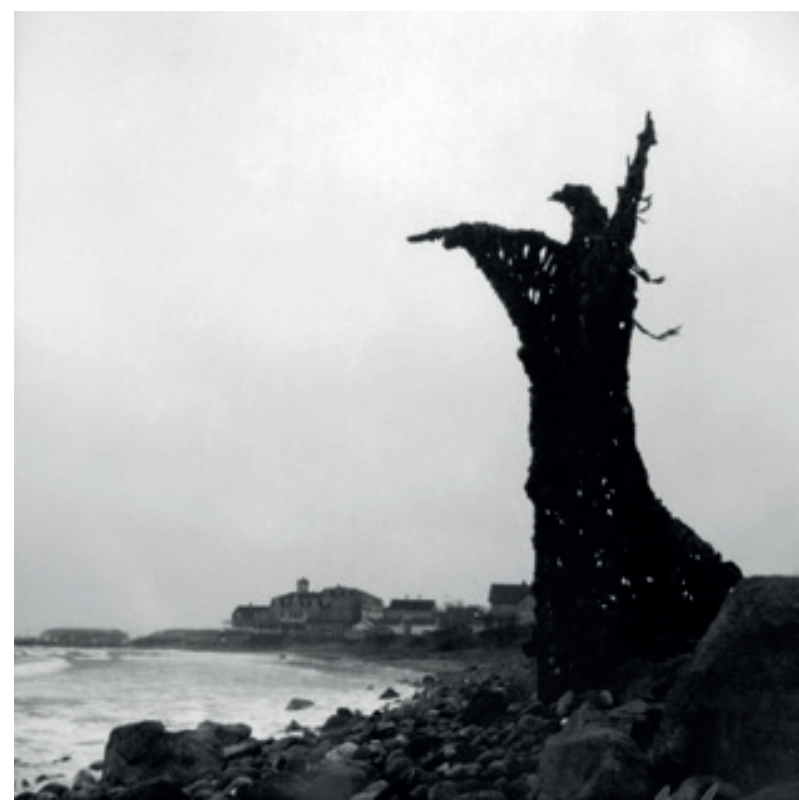

Escultura de sargazo. Crescent Beach. Block Island. los derechos civiles de los $50 \mathrm{y}$ 60 , o el ingreso del sonido latin en el rock de un Carlos Santana y su subsecuente explosión en el soul chicano, o la visualidad que ganaron entonces las supervivencias indígenas del mismo país del norte, o el boom de la salsa vía el exilio cubano y la migración portorriqueña- dejaron una puerta abierta a un campo en el que, no sin lucha e intención reivindicativa, cabría el cortante discurso de acero de Ccopacatty.

\section{El estilo}

Aunque es imposible pensar que no se ha nutrido del indigenismo sabogaliano - ¿qué bellasartino puede decir que no ha absorbido tal legado, sea para recrearlo y transformarlo, para reaccionar contra él o para pre-

tender ignorarlo?-, el suyo es un arte que aborda la problemática del ser nativo americano desde el lado opuesto al de Sabogal. Los sujetos que Ccopacatty plasma no son los mismos que el creador del indigenismo identificó y contribuyó a desactivar creando una estereotipia voyeurista y nacionalista. Ccopacatty habla desde el extremo opuesto: deconstruye el estereotipo y lo vuelve a humanizar, a dotar de vida, de espíritu, a través de una muy personal forma de ultraexpresionismo aymara que es indígena, no indigenista, al mismo tiempo que es universal, pues su centro es la forma humana (y su tragedia), mediatizada por el aprendizaje académico. Nunca está ausente de ninguna de sus piezas la posición que reclama el reconocimiento de la dignidad de comunidades por siglos despojadas, conquistadas, discriminadas: el suyo es un discurso rebelde y de denuncia. Cuando no es el retrato crudo de la Conquista, con sus armas y sus heridas, es la representación del hombre y la mujer andinos en actitud triunfante o festiva, en situación de trabajo o de júbilo y juego; todas acciones que son esencia de lo humano. Nunca están sus sujetos en una inactiva contemplación, cuando están quietos es porque son objeto de un acto de poder que se ejerce sobre ellos. Pero no; los sujetos de Ccopacatty están siempre en un vertiginoso movimiento que rasga los aires con sus filos.

Ccopacatty había optado por el trabajo con metal de desperdicio (la mayor parte de sus esculturas, de gran o mediano formato son de hierro forjado, acero o acero inoxidable) para exprimirle sentido con el martillo y el soplete. "Desde sus inicios, es un artista sin moldes", explica el escultor Millard Llanque, promotor de la exposición-homenaje Ccopacatty. Una vida de fuego y metal, exhibida en el Centro Cultural de Bellas Artes entre mayo y junio de 2019 (Chaman, 2019, p. 4). Con este rudo vocabulario fue logrando una síntesis visual no exenta de violencia (la violencia del martillo y el fuego, la amenaza cortante de las agudas puntas y los dentados filos de esas navajas gigantes), en la que sus piezas se componían de pedazos que, como huesos, daban estructura a un sueño, el sueño de la vida. Su concepción del mundo, en plena era de debates ideológicos y aguerridas militancias, se había volcado hacia el humanismo, un humanismo universalista enraizado en la herencia aymara; 


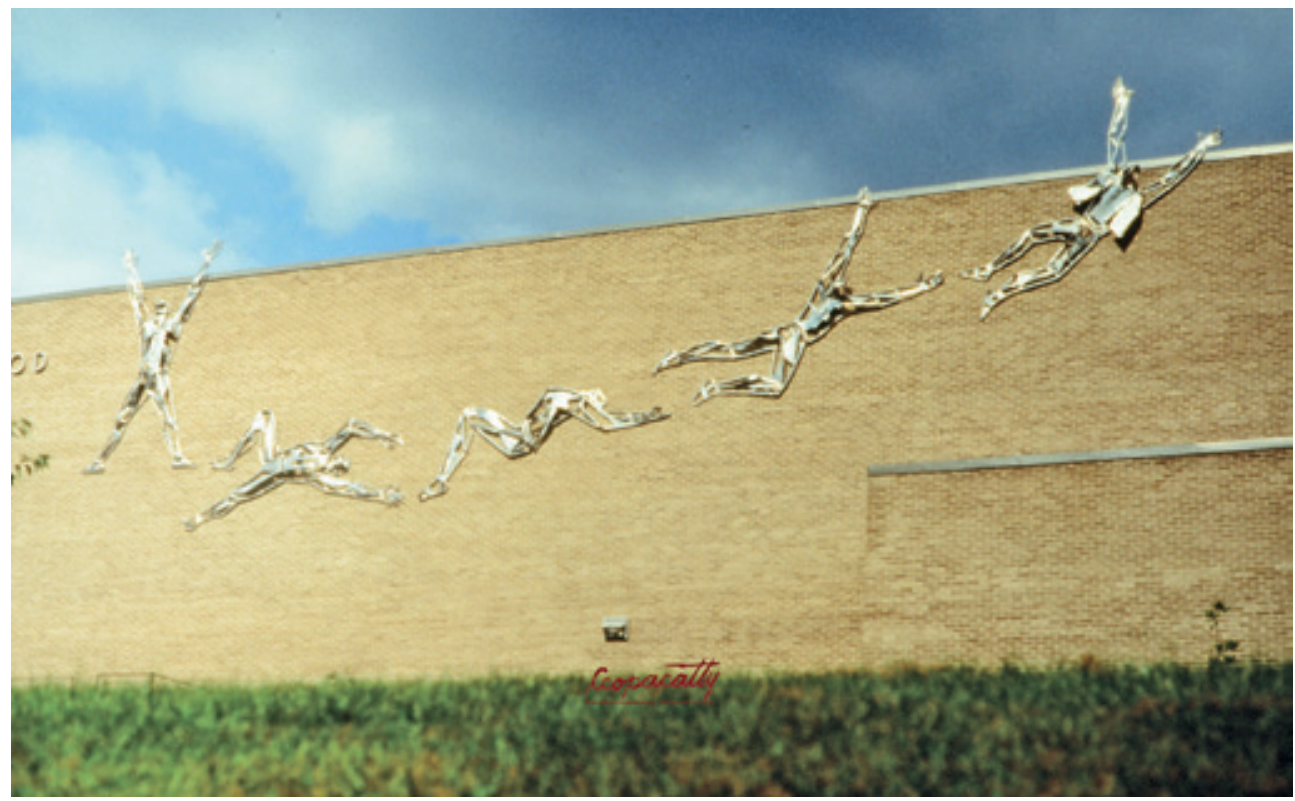

Evolution. Acero inoxidable. Norfolk, Virginia.

una visión indígena que ha absorbido la alta cultura occidental a través del filtro bellasartino, que incluye al indigenismo; una propuesta estética y espiritual que enfrenta al vértigo de la posmodernidad tecnológica de los Estados Unidos de los 80 y se incrusta en ella, además, con éxito comercial —en el 2005 respondía descuidadamente a la pregunta expresa de Loayza sobre el costo de un proyecto: "puede ser de cien mil dólares para arriba"-.

Se diferenciaba así de las tendencias vigentes en el ámbito de la escultura de gran formato en Bellas Artes, orientadas a la estatuaria tradicional. Durante sus últimos años en Lima (la segunda mitad de los 70), toma el camino del residuo industrial por vías distintas a las de sus colegas, desarrollando poco a poco un estilo que dialogaba sin saberlo con lo que empezaba a ocurrir del otro lado del campo artístico limeño: unos años antes del paso de Ccopacatty por Bellas Artes, la escultora italiana Anna Maccagno promovía en la Facultad de Arte de la Universidad Católica un acercamiento al trabajo en el ámbito industrial que se había abierto a través de la creación del Servicio Nacional de Adiestramiento en Trabajo Industrial (Senati), transformando sus talleres en espacios para la formación artística. Los curadores Juan Peralta y Daniel Contreras (2019) describen esta relación en su texto curatorial para la exposición colectiva Madre Tierra V. Del Patrimonio industrial al cuerpo escultórico junto con un escenario en el que los artistas en formación del entorno de la Universidad Católica a fines de los 60 comenzaban a utilizar chatarra y desperdicios industriales para elaborar su discurso estético. Madre Tierra $V$, exhibida en las galerías de Petroperú en junio del 2019, tiene sus antecedentes en otra importante colectiva curada también por Peralta y Contreras, Acero, auspiciada por Aceros Arequipa, en el Museo de Arte Contemporáneo de Lima entre noviembre del 2013 y enero del 2014; ambas buscaron trazar los derroteros del trabajo de artistas peruanos con el hierro y, especialmente, el acero, pero en ninguna se incorporó la obra de Ccopacatty (Museo de Arte Contemporáneo de Lima, 2014).

Mientras tanto, entre los artistas bellasartinos cuya obra protagonizan el hierro forjado y la soldadura, los autores enlistan: "a lo largo de la década de 1960 Víctor Delfín, desde su taller en Barranco y Alfonso Moreno Elías, con El Yunque y posteriormente la Galería del 


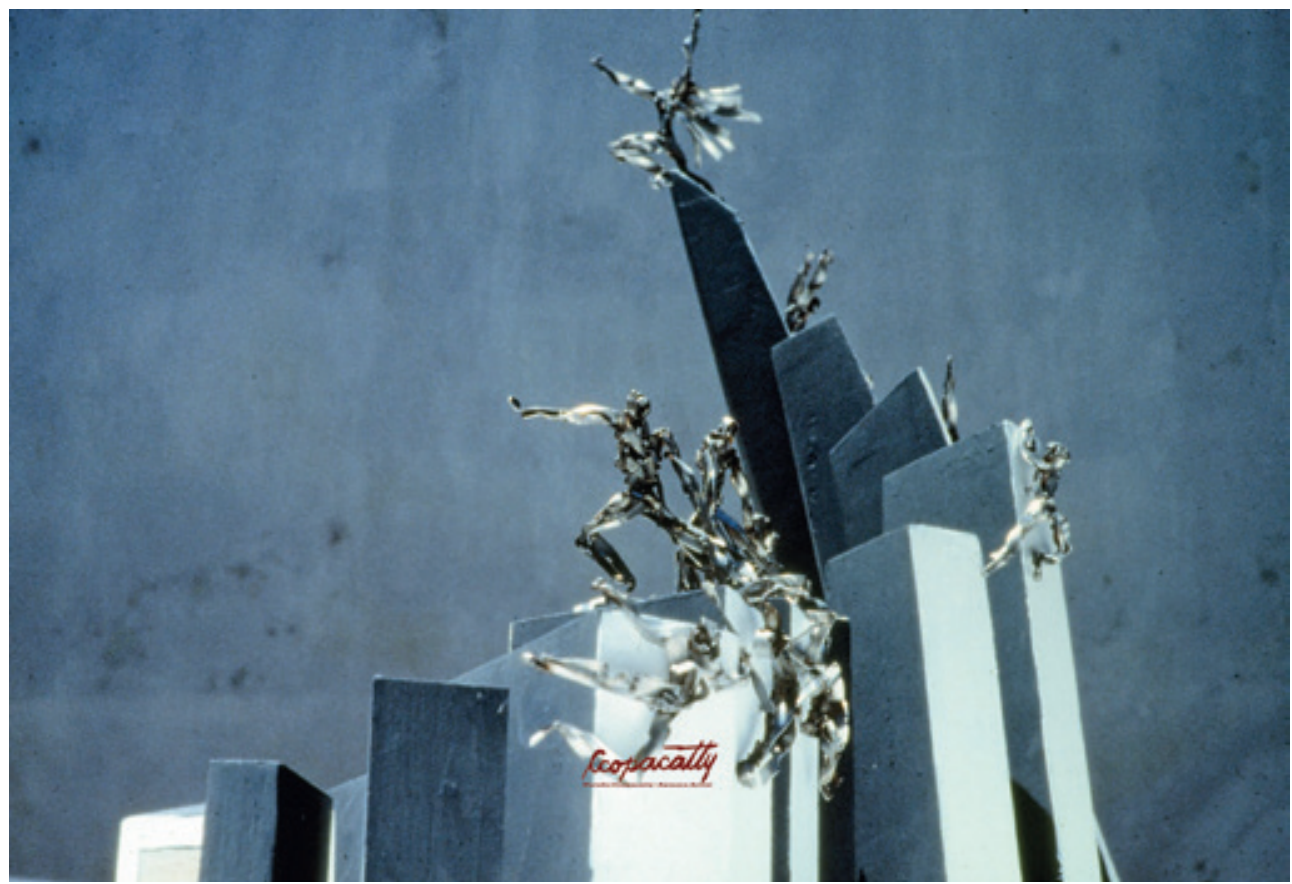

Maqueta monumento a la batalla del Alto de la Alianza. Tacna.

Fierro" (Peralta y Contreras, 2019). En su nota para Identidades en 2005, a partir de una entrevista telefónica con Ccopacatty, Daniel Contreras contextualiza: "Era una época en la cual era ya considerable el número de escultores: Alberto Guzmán, Herman Piscoya, Joel Meneses, Amelia Weiss solo por citar algunos de dicha escuela [la Ensabap]" (2005). De un modo u otro, indirecta o directamente, Ccopacatty habría abrevado de ese contexto pues, como indican Peralta y Contreras, se metaforizaban también en las artes las transformaciones sociales y políticas del momento: la representación a través del metal corroído y filoso, la sensación del óxido, tenían un lugar natural en la imagen del desarrollo desigual, del desborde popular, de la industrialización a trompicones, de la sociedad en proceso de viraje y multiplicación identitarios. Sin embargo, Ccopacatty conservará casi siempre un figurativismo dramático, desmesurado, mientras sus contemporáneos zigzagueaban entre el realismo y la abstracción. Mientras el artista aymara ocupaba el espacio público, la mayoría de sus colegas se veían recluidos al pequeño formato.

Además de la medalla de oro (La tragedia de los dioses, fue la pieza de graduación), Ccopacatty había sido reconocido en 1975 por su trabajo en metal y en pintura mural en Bellas Artes; esta última faceta, el mural público, es también muy importante dentro de su obra (Ccopacatty, s. f.). Dedicó los siguientes años (1976-1979) a seguir formándose en la propia Bellas Artes con prácticas posgraduales, lo que significa que colaboró en los talleres de los principales fundidores de esculturas públicas en el Perú, hasta llegar a dominar las diversas técnicas. Así, el desarrollo de su geometría rota, irregular, de sus acabados tan expuestos a la intemperie (son célebres sus Esculturas de sargazo en las playas de Crescent Beach, Block Island, una de las cuales alcanza los seis metros de altura, con algas marinas que, arrojadas por las olas, van cubriendo como hiedra a la estructura y creando una silueta antes solo sugerida) consiguen un efecto dramático al exponer en el metal el drama de su propio origen en tanto el alma que le es arrancada a la Tierra. 


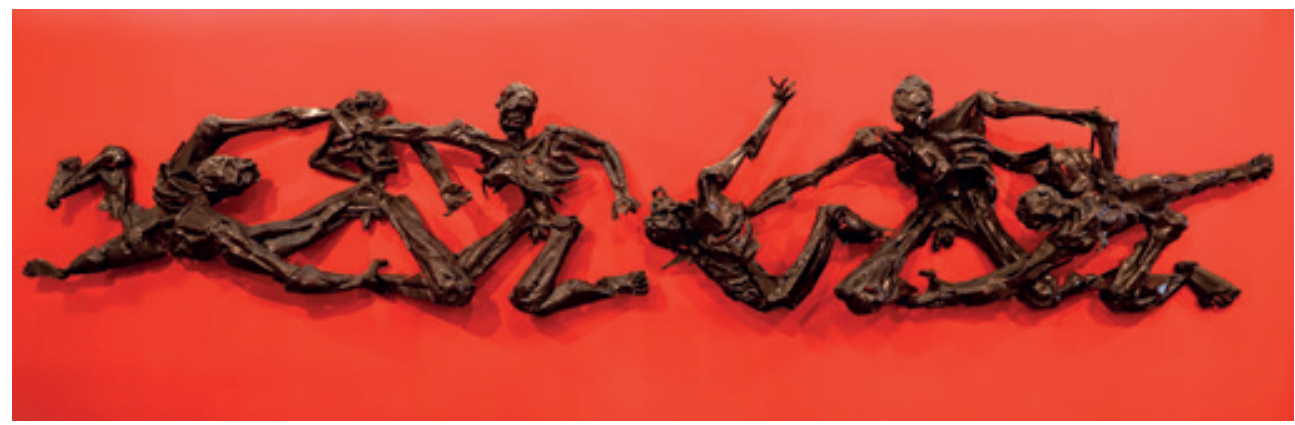

Pedro Ccopacatty. La tragedia de los dioses. Fotogafía de Rosana Monteverde. Cortesía del Centro Cultural de Bellas Artes.

Pike (2019) ha destacado el elemento triunfante en los personajes de la obra de Ccopacatty. Claro que no está siempre ahí, pues una de sus obsesiones es la violencia (su hilo conductor es en todo caso el movimiento), pero buena parte de sus esculturas exhibe a hombres y mujeres que arquean la columna y levantan el rostro y las manos, como en Unity, en Norfolk, Virginia, o en Grito al viento. Su relación con lo proletario no está solo en el símbolo del taller en el que produce: Steel Workers, en Portsmouth, Virginia, plasma una visión heroica de los obreros del acero: una obra proletaria, no industrial, no importa que hubiese sido comisionada por la compañía metalúrgica. El sumum de su estrategia visual bien puede estar en La tragedia de los dioses, temprana pieza de acero de gran formato (1,7 metros de extensión horizontal) exhibida en el Centro Cultural de Bellas Artes en la reciente exposición, que incorpora casi todos los estilos plásticos (metálicos, minerales quisiéramos decir) del autor: el ensamblaje de la acción en esqueletos de planchas de (en este caso) acero; el aire que circula entre las piezas y las mueve (otro hermoso ejemplo de esto es La ronda infantil, en Nueva Jersey), la falsa perspectiva alcanzada mediante el achicamiento de elementos de la anatomía humana, estrategia que usa sobre todo en las piezas de relieve flotante sobre un muro (como La tragedia de los dioses o la fachada de la Biblioteca de la Universidad del Altiplano); el arqueamiento extremo de la columna vertebral sin llegar a posiciones anatómicamente imposibles, manipulaciones extremas de la figura natural que llevará también a sus toros y caballos; la tensión muscular lograda a través de las cortantes láminas y la soldadura, cuyos puntos son como tendones en esos cuerpos rasgados; esa sensación de que al acercarte a la obra, esta te lastimará. En sus propias palabras: "Busco la dinámica del movimiento y externalizo la estructura interna de la forma humana" (Ccopacatty, s. f., énfasis nuestro). En otra parte describe:

Mis esculturas se relacionan con el tiempo y la distancia. Mi trabajo me recuerda mi historia, mi espíritu no olvida esa dimensión ancestral. Como escultor tengo la misma urgencia de conectar el pasado con el futuro; sigo respondiendo esa pregunta. (Ccopacatty. Art Constructions, s. f.)

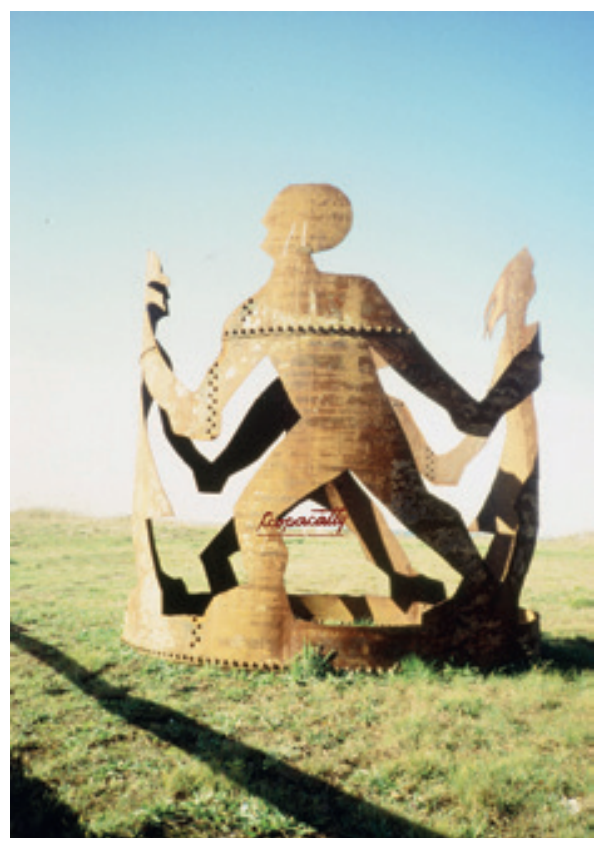

Ronda infantil. Hierro. Rhode Island. 


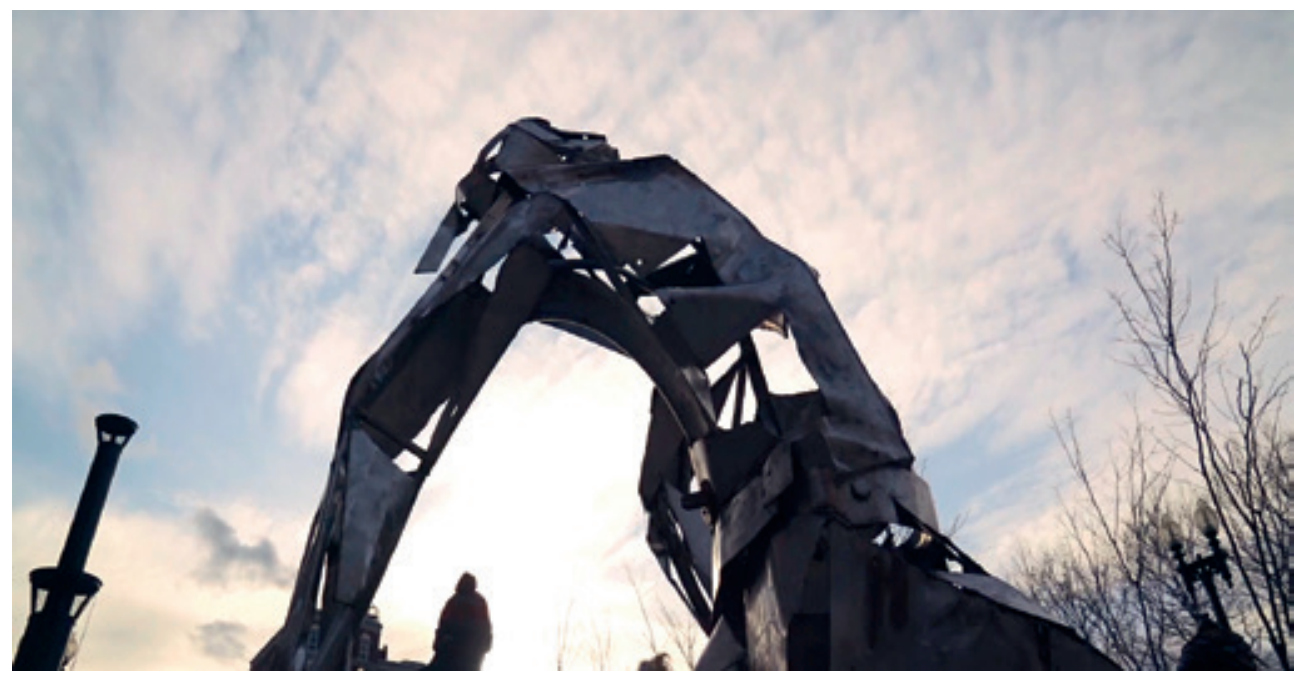

Generations (detalle). Kennedy Park, Providence, Rhode Island.

Con este bagaje a cuestas, hacia 1985, cuando establece su taller en Rhode Island, Ccopacatty ya ha colocado varias esculturas monumentales y pinturas murales, todas comisionadas por instituciones, en el estado de Virginia, Estados Unidos. 40 años después suman decenas las piezas de gran y mediano formato que el artista ha instalado en lugares públicos y privados a lo largo y ancho de su país de residencia.

\section{La trayectoria}

Quizá por su temprana emigración a los Estados Unidos, Ccopacatty pasó desapercibido a los historiadores y críticos de arte en el Perú; no queremos creer que este olvido es producto de consideraciones que nos obligarían a sospechar actos de discriminación (por su estilo, por sus temas, por su procedencia, por su color de piel, por su lengua materna, por su origen socioeconómico). La catalogación completa de su obra es un reto que bien valdría el esfuerzo de algún tesista de grado en historia del arte (tendría que tener presupuesto para viajar bastante por los Estados Unidos y un poco más por el Perú). Un catálogo (que hemos consultado de los archivos del artista) publicado en los Estados Unidos alrededor de 1985, enlista sus exhibiciones en el Perú de los años anteriores a 1981, demostrando que se trataba de un artista joven que había estado presente en salas y exposiciones importantes, junto con otros que sí serían incluidos en el canon limeño. Participó en colectivas en las galerías de la Asociación de Artistas del Perú, de Arte Sol, Leyva, Petro Perú y Galdós Rivas, y expuso en instituciones como el Ministerio de Industria y Turismo, la embajada de los Estados Unidos y el Museo Nacional de Arte. Durante esa época se presentó también individualmente en los espacios de Galería de Arte Sol, Galería Leyva y Viernes de Lima.

Y en otras ciudades del Perú: en octubre de 1980 exhibió en la Casa Basadre de Tacna un proyecto para el monumento memorial de la Batalla del Campo del Alto de la Alianza, hoy uno de los landmarks de esa ciudad sureña. Era uno de sus primeros encargos de obra pública, pero por alguna razón que el artista no desentraña, no se llevó a cabo. Sobre un diseño arquitectónico y conceptual -columnas de concreto que se disparan hacia el cielo en procesión- de Julio Enrique Vargas Giles, Eduardo Ramal Pesantes y Jorge Espinoza Cáceres (anónimo, 2016), Ccopacatty imaginó y dibujó figuras heroicas, casi fantásticas, que volaban entre los pilares asimétricos del monumento aumentando su dinamismo, su congelado momentum. El proyecto fue finalmente realizado por Holger Carpio Dextre, experimentado escultor que, si bien utilizó una técnica similar a la de Ccopacatty -la plancha de metal-, no 
alcanzó el grado de expresividad y movimiento que prometían los dibujos y la maqueta del artista aymara. El parentesco entre ambas versiones, el proyecto diseñado por Ccopacatty y las esculturas de acero de Carpio, es sin embargo notable.

A su llegada a los Estados Unidos, Ccopacatty se incorporó a los circuitos artísticos de la costa Noreste con participación en colectivas en Virginia Beach Art Center, Norfolk y el Museo Muscarell. Realizó también individuales, a razón de una anual, en diversos puntos de Virginia, y comenzó exitosamente a instalar comisiones públicas y privadas. Su texto indígena rasposo y rudo, claro y moderno, dialogó con vanguardias tecnológicas como el minimalismo y el op art (Contreras, 2005) e impuso su mirada andina en territorio yanqui.

La tragedia de los dioses se quedó en el Perú, instalada de manera permanente en la Galería de Arte Sol. La obra vivirá aventuras; una fuente de los archivos del autor señala que fue adquirida por la municipalidad de San Isidro, mientras que en el 2005, Loayza documenta su "donación" al centro de espectáculos Brisas del Titicaca, donde fue instalada con descuido, hasta ser rescatada por el artista para la muestra Ccopacatty. Una vida de fuego y metal en el Centro Cultural de Bellas Artes (ojalá, soñamos, fuera la obra adquirida por el alma mater). Unity fue un encargo del Centro de la Comunidad Judía de Norfolk; Life Run, Mercado campesino y el mural Campesinos son comisionados para el centro de la misma ciudad; La Peck Metal Co. de Portsmouth, Virginia, comisiona Steel Workers, en la que Ccopacatty honra la fortaleza de los trabajadores siderúrgicos con el producto de su esfuerzo, el acero; la hermosa Ronda infantil se instala temporalmente en una escuela Grito al viento también queda temporalmente en el Museo Muscarell, para ser adquirida por el Chrysler Museum of Art de Norfolk. También trasladó obra del Perú a los Estados Unidos, como sus briosos Caballos de hierro, adquirida después por una colección particular en Los Ángeles, California, y Minero -otro tema proletario-, que será incorporada a la embajada del Perú en Washington D. C. Mientras realiza estas tareas, emprende otros proyectos. Y va perdiendo la cuenta de cuántos y dónde los deja; avanza sin preocuparse por si su nombre aparece en reseñas, críticas o catálogos.

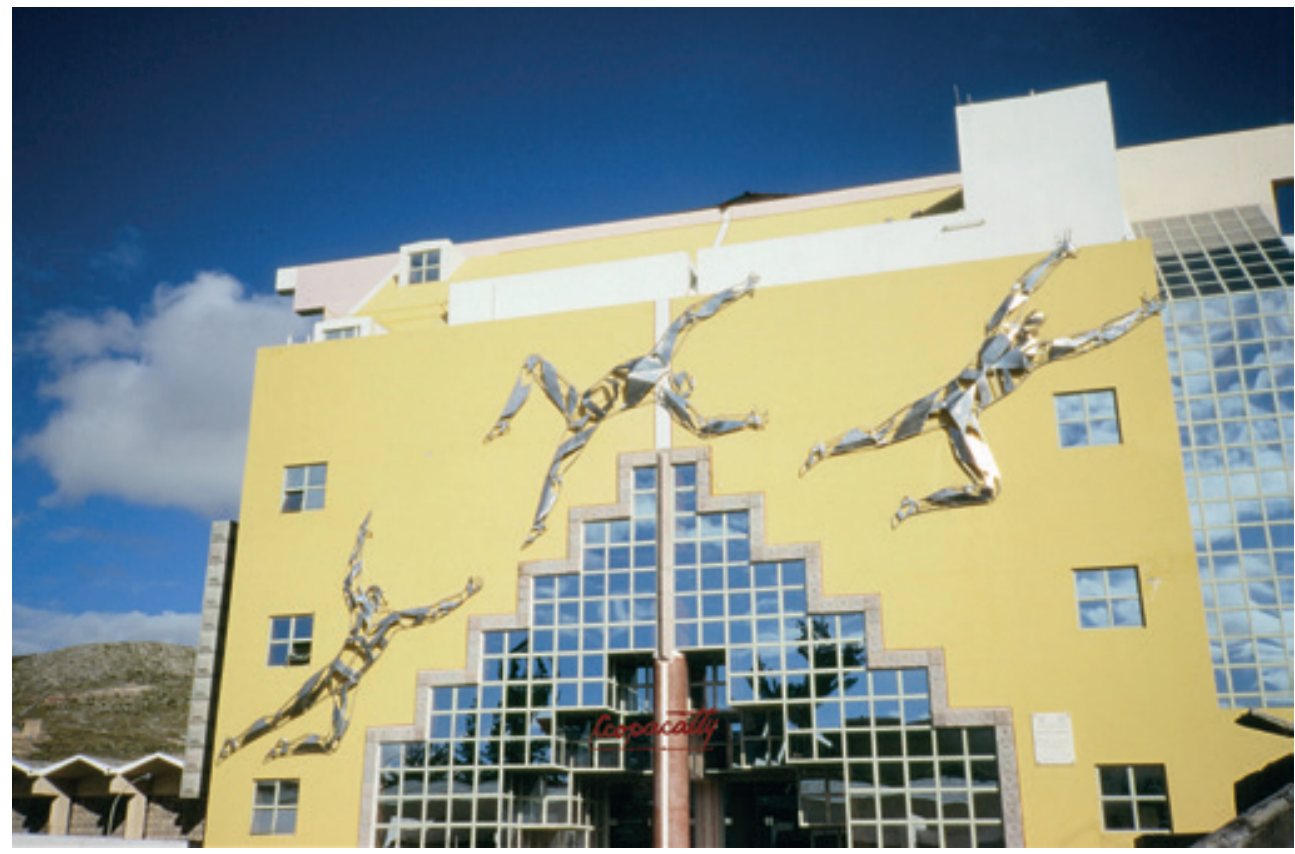

Transformación. Acero inoxidable. Universidad del Altiplano, Puno. 


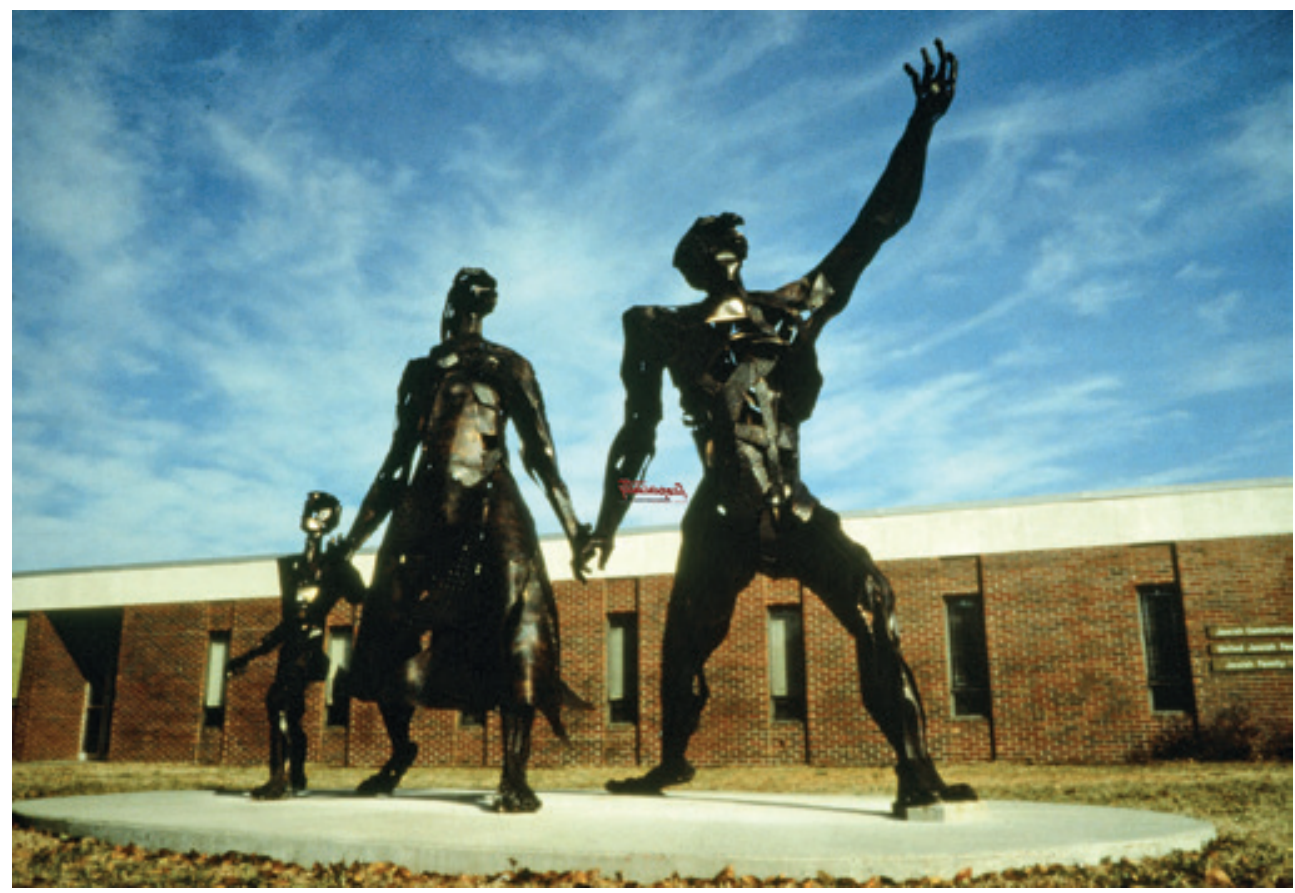

Unity. Hierro. Norfolk. Virgina.

A partir de 1986, con su taller y galería ya establecidos en Rhode Island, continúa una incesante actividad de la que no siempre lleva registro. Su personalidad vertiginosa lo conduce al siguiente proyecto, trabaja sin pausa y con ello va fijando el sello de una visión totalmente personal de la escultura pública, depurando el fruto de lo que había sembrado con La tragedia de los dioses. Su firma está en los ángulos cortantes de sus piezas, que siguen siendo instaladas en diversos lugares, a veces por comisión pública, otras por particulares, hasta que en 1994 es reconocido y celebrado a través de la simbólica llave de la ciudad de Providence, Rhode Island, su residencia adoptada.

En 1996 vuelve al Perú para instalar su Transformación en la fachada de la biblioteca de la Universidad del Altiplano en Puno. Volverá a participar con pintura mural en Moquegua en el 2000. Poco después es nominado al Premio a la Excelencia por la Sociedad de Escritores y Artistas de la Organización de las Naciones Unidas, organización que finalmente lo reconocerá "por su trabajo de relevancia social como escultor y muralista", en 2015, año de intensa actividad tanto en los Estados Unidos como en el Perú, donde el escultor Millard Llanque lleva ya algún tiempo promoviendo su reencuentro con el alma mater. Finalmente el encuentro sucede en la exposición homenaje de mayo-junio de 2019, en el Centro Cultural de la Ensabap, formando parte de las conmemoraciones por el Centenario de la Escuela. El proyecto había sido propuesto por Llanque en la convocatoria lanzada en el 2017 con miras al Centenario.

\section{La relevancia}

Ccopacatty es un gran ausente del registro académico del arte en el Perú. De no ser por las acciones de promoción emprendidas por Llanque con el decidido apoyo de Rosalee Pike, que estableció su residencia en el Perú, y por la receptividad de la Ensabap durante la celebración de su Centenario, este autor de relevancia internacional seguiría fuera de la 
historiografía del arte peruano, habitando unas cuantas notas de prensa aisladas durante casi 40 años. Queda por realizar una catalogación completa de su trabajo y un registro fotográfico que permita el análisis pormenorizado. Queda también pendiente el análisis de su aporte al corpus de la obra estética peruana del siglo XX y principios del XXI por un sector académico que lo ha ignorado sistemáticamente. Mientras la gran crítica lo pasa por alto y la mirada retrospectiva se olvida de incluirlo en un proceso al que pertenece por derecho, su expresionismo aymara perdura: el acero resiste la corrosión; la expresión del hierro se alimenta de ella. Vuelve al Perú para inaugurar su muestra-homenaje en Bellas Artes y parece disfrutar por encima de cualquier cosa la entrevista que da en aymara para la televisión gubernamental. Se niega rotundamente a dar más entrevistas, pero en esa, hablando en su lengua materna con la joven periodista que lo interroga, se explaya, sonríe, muestra, alza la voz. Nos da a nosotros pretexto para señalar su sitio en el proceso del arte peruano contemporáneo y asegurarnos de que no pase más inadvertido, pues representa nuestra pluralidad cultural desde mucho antes de que los nuevos paradigmasde los estudios culturales nos permitieran dar ese nombre al conjunto que somos. A su modo, la escultura rebelde y amenazante de Ccopacatty sigue siendo un grito de lucha por la igualdad.

\section{Referencias bibliográficas}

Anónimo. "Museo de sitio del Campo del Alto de la Alianza". En: Fotos e Imágenes del Perú (blog). Septiembre de 2016. Recuperado de http:// imagenyfotos.blogspot.com/2016/09/museo-desitio-del-campo-del-alto-de-la.html

Bell, D. Las contradicciones culturales del capitalismo. México: Conaculta / Editorial Patria, 1977.

Ccopacatty. Catálogo promocional de la obra, Rhode Island, s.f. [ca. 1995].

Ccopacatty. Art Constructions. Catálogo promocional de la obra publicado en Rhode Island, s.f. [ca. 1986].

Chaman, C. "De la agonía a la vida". En Variedades 596 (suplemento de El Peruano), 28 de junio de 2019.

Contreras, D. "Crónicas Aymaras desde Rhode Island". En Identidades (suplemento cultural de $E I$ Peruano). 18 de abril de 2005.

Hoyos, H. "Ccopacatty. Visiones y perspectivas sobre la obra del artista". Participación en el conversatorio, grabación del autor. Lima: Centro Cultural de Bellas Artes, 19 de junio de 2019.

Loayza, J. Sin título (nota sobre Ccopacatty). En La República. 11 de junio de 2005. Recuperado de https://arepublica.pe/ archivo/300527-aymara-art/

Magdalenadigital12. "Un personaje especial de Magdalena del Mar. Una entrevista al 'Rey de la chatarra' Mario Torres Sánchez". En: Ven y conoce Magdalena (blog). 7 de noviembre de 2012. Recuperado de https://venyconocemagdalena.wordpress.com/2012/11/07/ un-personaje-especial-de-magdalena-del-mar/
Museo de Arte Contemporáneo de Lima (MAC). Acero. Página en la sección "Exposiciones" de la página en internet del museo. Enero de 2014. Recuperado de http://www.maclima. pe/?exposiciones $=$ acero

Peralta, J., y Contreras, D. Madre Tierra V. Del Patrimonio industrial al cuerpo escultórico. Texto curatorial de la exposición (copia digital del texto preliminar proporcionada por los autores). Lima: Petroperú, 2019.

Pike, R. Ccopacatty. Una vida de fuego y metal. Texto curatorial, programa de mano. Lima: Centro Cultural de Bellas Artes, 2019.

Vivanco, C. "Ccopacatty. Visiones y perspectivas sobre la obra del artista". Participación en el conversatorio, grabación del autor. Lima: Centro Cultural de Bellas Artes, 19 de junio de 2019.

Llanque, M. Ccopacatty y la escultura monumental en metal. Expediente de inscripción del proyecto a la Convocatoria de Proyectos Artísticos de la Ensabap hacia el Centenario, Lima, 2017.

Recibido el 23 de julio del 2019 Aceptado el 20 de septiembre del 2019 